\title{
Representaciones sociales, inclusión de género y sexo en los juegos recreativos tradicionales de la calle de Caldas-Antioquia, Colombia*
}

\author{
Social Representations, gender and inclusion of tradicional games \\ street (Caldas-Antioquia, Colombia) \\ Representações sociais, gênero e inclusão dos jogos recreativos tradicionais \\ da rua (Caldas-Antioquia, Colombia)
}

Alejandro Vásquez Bernal

Instituto Universitario de Educación Física, Universidad de Antioquia, Colombia. Tel: 3013706710 , alejandro.vasquezbernal@gmail.com

\begin{abstract}
RESUMEN
Este texto da cuenta de una investigación desarrollada sobre los Juegos Recreativos Tradicionales de la Calle (JRTC) que se realizan en el municipio de Caldas (Col.) ininterrumpidamente desde hace treinta y dos años. Tiene por objeto el conocimiento de las representaciones sociales (RS) que poseen los estudiantes sobre estos juegos y la identificación del potencial inclusivo de género y sexo que esta propuesta educativa contiene. Se trata de un estudio cualitativo etnográfico, donde el investigador, profesor de una de las instituciones estudiadas, hace las veces de observador participante. La información se recoge a través del diario de campo y la foto-discusión. Con relación a la inclusión de género y sexo, el estudio, inductivamente, encuentra en la autodesignación y en la heterodesignación de los y las jóvenes, dos herramientas conceptuales potentes que permiten identificar -en sus representaciones sociales- el potencial inclusivo de JRTC.
\end{abstract}

Palabras clave: educación, currículo, representaciones sociales, género, juego.

\begin{abstract}
This article reports on an investigation conducted under the Motor Masters in Human Development at the University of Antioquia, Colombia (2011-2012). The study aim is to understand the social representations (RS) of the students of Caldas (Antioquia) on the traditional Street Games (JRTC) and their inclusiveness potential. This is a qualitative study is based on a school ethnography where the researcher acts as a participant observer. The information is collected through journals, the pictorial ethnography and photo discussion. This paper reports results on the inclusiveness potential of gender and the sexist practices of JRTC in student performances.
\end{abstract}

Key words: education, social representations, curriculum, games, gender.

* $\quad$ Este artículo fue solicitado por la Revista Estudios Pedagógicos en diciembre del 2011 en el contexto del proyecto de Investigación FONDECYT (Fondo de Investigación Científica y Tecnológica) No 11110016 , titulado "Educación Física y su función de transformación de las desigualdades sociales: profesorado del área y documentación ministerial". El artículo fue aceptado en junio de 2012. La investigación, realizada en el marco de la Maestría en Motricidad y Desarrollo Humano de la Universidad de Antioquia, Colombia (20112012), cuenta con la financiación del CNPq (Brasil) e INDEPORTES Antioquia (Colombia). Hace parte del macroproyecto internacional "Documentação e interpretação de boas praticas pedagógicas nos processos de educação do corpo na escola", desarrollado por grupos de investigación de las universidades: Santa Catarina (Br.), Rio de Janeiro (Br.), Nacional de la Plata (Arg.) y la de Antioquia (Col.). 


\section{RESUMO}

Relata-se uma pesquisa desenvolvida no âmbito do Mestrado em Motricidade e Desenvolvimento Humano da Universidade de Antioquia, Colômbia (2011-2012). Toma-se como objeto de conhecimento as representações sociais (RS) dos alunos de Caldas (Antioquia) sobre os Jogos Recreativos Tradicionais da Rua (JRTR) e seu potencial inclusivo. Trata-se de um estudo qualitativo baseado na etnografia escolar onde o pesquisador age como observador participante. A informação é recolhida por meio de diário de campo, da fotoetnografia e a da foto discussão. Informam-se resultados sobre o potencial inclusivo de gênero e das dinâmicas sexistas de JRTR a partir das representações estudantis.

Palavras chave: educação, representações sociais, currículo, jogos, gênero.

\section{INTRODUCCIÓN}

En el departamento de Antioquia (Colombia), se desarrollan dentro y fuera de la escuela una gran cantidad de prácticas relacionadas con la educación física, la recreación y el deporte; todas ellas expresan distintos niveles de inclusión. En la Universidad de Antioquia, el grupo de investigación Prácticas corporales, sociedad, educación y currículo $(\mathrm{PES})^{1}$ se interesó por investigar el potencial curricular, histórico, cultural y social de los Juegos recreativos tradicionales de la calle, presupuestándolos de partida como una buena práctica educativa.

Los Juegos Recreativos Tradicionales en la Calle (JRTC) son una fiesta alrededor del juego tradicional que se celebra en la municipalidad caldeña desde hace treinta y dos años de manera ininterrumpida. El pueblo, a mitad de cada año, se convoca en escuelas, calles y parques para celebrar alrededor del juego tradicional. Dentro del macroproyecto internacional se constituye el subproyecto "Representaciones sociales del estudiantado de Caldas ${ }^{2}$ (Antioquia) sobre los JRTC en el contexto de lo curricular". Este artículo presenta resultados sobre el potencial inclusivo que desde las voces estudiantiles, y desde una perspectiva de las relaciones de género y sexo, poseen los JRTC. Para ello se seleccionaron seis instituciones educativas de carácter público (cuatro urbanas y dos rurales). Cada una de ellas informa en su proyecto educativo institucional la participación en las tres fases de los Juegos $^{3}$ (intramural, municipal y nacional). Por cada institución se seleccionaron cuatro estudiantes, procurando igual número de hombres y de mujeres.

Muchas de las investigaciones en el campo educativo (situación que se extiende al sub campo de la educación física, el deporte y la recreación) privilegian la voz del investigador y escasamente dan la voz al profesorado ${ }^{4}$ y ni qué decir de la voz del estudiantado; estos últimos, a quienes se les asigna hoy como centro de la acción educativa, han permanecido silenciados e invisibilizados. Hay una buena cantidad de estudios: Huberman, 1993; Sikes, Measor y Woods, 1985; Riseborough, 1981 (Cit. En Hargreaves, 2000: 3) que dan cuenta de este drama estudiantil, el cual a veces se ve profundizado por un profesorado "desencantado" o a la "defensiva" que no otorga una prioridad en sus problematizaciones a la voz de los alumnos. Hargreaves (2000) referencia otras investigaciones (Siskin, 1994;

\footnotetext{
1 Grupo de investigación con registro Colciencias

2 Caldas, municipio de 70.000 habitantes perteneciente al área metropolitana del Valle de Aburrá (3.900.000 habitantes), a esta ciudad-región pertenece la ciudad de Medellín.

3 Con la palabra Juegos le gente del pueblo se refiere a los Juegos recreativos tradicionales de la calle, en este articulo será utilizada de bajo esta idea.

$4 \quad$ Para profundizar en el problema ver Hargreaves (2000).
} 
Book y Freeman, 1986; Noddings, 1992; Goodson, 1988; Ball, 1989) que demuestran como los profesores están más interesados por su asignatura y por una transmisión satisfactoria que por aquello que pasa con sus estudiantes. Lo anterior habla de un modelo de escuela y un modelo investigativo basado en una relación de poder, en la cual al estudiantado se le asigna una categoría inferior, silenciados. Es el investigador o el profesor quien tiene el mando; son sus voces las que cuentan.

En la práctica educativa se viene superando esta situación. Para Hargreaves (2000) esto no implica un desconocimiento de la voz profesoral. El interés por la voz del estudiante estaría mostrando la apertura en el campo educativo de voces antes silenciadas. Hipotéticamente, la voz del estudiantado de Caldas, en su intervención educativa, habría sido conculcada, soslayada o pasada por alto. Los estudiantes son activos, juegan, hacen logística, sudan, ganan, pierden, compiten, reciben o no el trofeo, pero los Juegos se hacen con ellos o a espaldas de ellos. Los Juegos son seleccionados, preparados por adultos, por funcionarios, por profesores, en su mayoría hombres. A los estudiantes nadie les ha preguntado qué quieren jugar, cómo se sintieron jugando, los ponen a jugar. Pocos les escuchan sobre cómo pasan los JRTC por sus sentidos y por su experiencia. Este estudio les da la voz, es una oportunidad para pensar los Juegos a partir del relato estudiantil, desde sus propios pensamientos y representaciones.

El estudio parte de un panorama inicial que se forma el investigador desde adentro de los Juegos. Esta aproximación, le permite la configuración de unos presupuestos hipotéticos que orientarán el proceso investigativo. Se destacan, con relación al asunto de género e inclusión, los siguientes: (1) A través de la información intergeneracional los JRTC reproducen el sistema de relaciones tradicionales de género hegemónico en la cultura caldeña. (2) Los estudiantes caldeños, poseen actitudes propias y curricularmente ocultas acerca de los Juegos. (3) En función de la condición de género, el estudiantado caldeño tiene una diversidad de opiniones (creencias) sobre la participación en los Juegos. (4) El estudiantado caldeño, desde sus imaginarios, desea unos Juegos diferentes a los que se desarrollan actualmente; Juegos distintos a los proyectados por el profesorado, las directivas y la familia. (5) Los JRTC conforman una práctica social que transmite sutilmente la exclusión social.

Se evidencia un asunto a investigar: las representaciones sociales que poseen los estudiantes sobre JRTC. En esta dirección, el estudio tiene como propósito la descripción y la comprensión situada, a nivel social y curricular, de las representaciones estudiantiles de género y sexo que definen las apropiaciones espaciales, temporales y corporales diferenciadas de los Juegos. Desde aquí, cabe preguntarse: ¿Cuál es el potencial inclusivo de género y sexo de los JRTC que se expresa en las representaciones sociales estudiantiles? Esta pregunta se interesa por las representaciones sociales hegemónicas y no hegemónicas identificables en las informaciones, actitudes, opiniones e imaginarios que sobre dicha problemática (inclusión de género y sexo en JRTC), posee dicho sector poblacional de Caldas. 


\section{PRECISIONES TEÓRICAS Y CONCEPTUALES}

\subsection{REPRESENTACIONES SOCIALES}

Según Hall (1997: 2), representar significa "usar el lenguaje para decir algo con sentido sobre [algo] o para representar de manera significativa el mundo a otras personas". Podríamos afirmar que con la representación, aquello de lo que se habla se hace presente en la mente, en la consciencia; es una sustitución, es el estar en lugar de, el re-presentar; es un acto mental donde algo es representado y ese algo se corresponde con un objeto, un acontecimiento, una persona, una idea. Jodelet (1984) agrega que no existe una representación social que no se asocie a un objeto, aunque este sea mítico o imaginario.

Las representaciones están mediadas por la cultura y esto tiene una implicación, su estudio pasa por una comprensión de las orientaciones y los sentidos que los sujetos (en este caso el estudiantado) desde sus contextos culturales (en este caso el escolar), les van otorgando en forma cambiante. Los campos de actuación social: el deporte, los carnavales, los rituales, las educaciones, el trabajo, la guerra y sus respectivos escenarios: el estadio, la cancha, la escuela, el parque, la calle, la iglesia, la fábrica, son territorios donde se opera la comunicación y el intercambio representacional.

Araya (2002) afirma que las representaciones sociales son fáciles de captar, pero advierte que no se puede afirmar lo mismo cuando se intenta hacer una definición conceptual, debido a la complejidad de los fenómenos de los que da cuenta; también por la diversidad de posturas que han hecho aproximaciones explicativas sobre el concepto de representación. Son dos las vertientes explicativas más reconocidas: la de Moscovici (1979), que define la RS como una modalidad particular del conocimiento, como un corpus de conocimientos, actividad psíquica organizada y orientada por medio de la cual los seres humanos hacen inteligible la realidad física y social; y la de Jodelet, que plantea que la RS intenta aprehender esencialmente nuestro entorno “...para comprender y explicar los hechos e ideas que pueblan nuestro universo de vida o que surgen en él, actuar sobre y con otras personas, situarnos respecto a ellas" (1984: 473). Estas aproximaciones teóricas consideran al sujeto como un productor de sentido, es decir, alguien que expresa en su representación el significado que da a su experiencia en el mundo social, allí se da la expresión de una sociedad determinada.

Sobre los contenidos de la representación social no existe aún un consenso en los estudiosos de la cuestión; parece que priman dos perspectivas: (1) la de Moscovici (1979), para quien existen tres contenidos en la representación social: la información, la actitud y el campo de la representación y (2) la perspectiva de Jodelet (1984), para quien además de la información y la actitud se deben incluir las opiniones y los imaginarios. Nuestro estudio se apoya en la idea que sobre los contenidos desarrolla Jodelet.

La información se relaciona con el grado de conocimiento que sobre "algo" tienen las personas. La actitud, para Fernández y Hernández (2005) da cuenta del componente más aparente, fáctico y conductual de la representación, además de ser la dimensión más estudiada por su implicación comportamental y motivacional de los actos educativos. Las opiniones dan cuenta del sistema de creencias que poseen los actores sobre "algo" (hecho, cuestión, situación, cosa, evento, fenómeno, acontecimiento). Las imágenes o los imaginarios, por su parte, dan cuenta de construcciones mentales situadas en el sujeto, en el grupo o en una generación determinada a partir de las indagaciones por el deber ser, el querer ser o por el sueño y la proyección que en este caso, poseen los estudiantes. 


\subsection{GÉNERO, SEXO E INCLUSIÓN CURRICULAR}

La noción de inclusión es polisémica; ha venido siendo relacionada con los asuntos étnicos, con la diversidad, el género, la integración y con el tema de las necesidades educativas especiales. El referente de la inclusión permite, desde este estudio, promover el debate de la educación inclusiva con relación a la tensión género y sexo en el juego. La UNESCO (2005) define la inclusión como un proceso de abordaje y respuesta a la diversidad de las necesidades de todo el estudiantado. Las prácticas sociales de alta convocatoria ciudadana, como es el caso de los JRTC, deben ser consultadas en su potencial inclusivo/exclusivo. Se evidencia una brecha entre el currículo prescrito y el currículo en acción. Una verdadera transformación del currículo, pensando la inclusión, debe empezar por una preocupación por la atención formativa y respetuosa de las identidades estudiantiles. Torres (2010: 94), sostiene que "[...] los idiomas, saberes, creencias, ritos, procedimientos, actitudes y valores que se utilizan en el entorno en el que se vive sirven para discriminar a alguien, quiere decir que estamos ante un sistema educativo injusto, o sea clasista y/o sexista, y/o racista, y/u homófobo". Los Juegos de la calle no son la excepción: también pueden ser clasistas, racistas, homófobos. El asunto ha sido motivo de intensas polémicas. En el campo del deporte y el juego, la discriminación en razón de los sellos de género y sexo han marcado históricamente la educación y la escenificación dentro del campo.

Hay una tensión entre los conceptos de sexo y género. Tubert (2003), refiriéndose al género, afirma que en su tratamiento abusivo, esta noción se hace polémica. Luego, Grinberg y Levy (2009) plantean que el género remite a una construcción histórica, cultural y social de naturaleza política que se apoya en las diferencias de sexo desde el punto de vista bilógico y en las diferencias sexuales de naturaleza psicológica. Lo contradictorio, según Tubert (2003), radica en que esta polaridad conceptual, marca en buena medida la reproducción de la clásica oposición entre naturaleza y cultura, y el moderno dualismo entre cuerpo y mente; oposiciones que han marcado el pensamiento occidental desde sus mismos orígenes. La valenciana Neus Campillo (2003) subraya que no se trata de una avanzada que pretenda descalificar el término de género, advierte que de lo que se trata es de no generalizarlo sustituyendo el concepto de sexo. En la revisión bibliográfica encontramos elaboraciones conceptuales específicas relacionadas con los conceptos de género y sexo que ayudan al tratamiento del asunto; nos remitimos a las nociones de rol de género, estereotipo de género, sexismo y a las nociones de autodesignación y heterodesignación.

Los roles de género, se definen como "un conjunto de tareas y funciones que se asignan a una persona o a un grupo de personas dentro de una cultura o un grupo social determinado" (Moreno 2000: 14). Para Mackie (Cit. en Moreno, 2000) las valoraciones, consideraciones y representaciones son las responsables del mantenimiento de los roles asignados socialmente a cada uno de los sexos; emergen así los estereotipos de género, definidos como creencias populares sobre los atributos que caracterizan a una categoría social específica. El sexismo, ${ }^{5}$ por su parte, se corresponde con "aquellas conductas

Según Páramo (2010) existen en la actualidad dos líneas del feminismo, una encaminada hacia la equidad que busca la igualdad entre hombres y mujeres, y la segunda denominada de género o diferencial que afirma que las mujeres son diferentes y por ello han sido discriminadas y acosadas. 
sociales discriminatorias basadas en el sexo de los individuos y en los roles socialmente aceptados" (Páramo, 2010: 181). Al valorar el currículo (explicito e implícito) de este tipo de prácticas, los distintos estudios coinciden en la presencia de dispositivos y estrategias discriminatorias. Los JRTC, en todas sus fases, no escapan a estos determinantes. La autodesignación es entendida como la capacidad que posee el sujeto de autodeterminarse, esta capacidad pasa por la autonomía, entendida por Moreno (2010) como: idea, valor, cualidad, condición,y práctica que habla de alguien que puede autodesignarse en contravía o como respuesta a fuerzas provenientes del afuera que pugnan por heterodesignarle o por integrarle a través de una consigna, una prescripción, una guía, un manual, un programa. En la heterodesignación no cuenta la propia voz, sino que el sujeto es condicionado por una voz externa que le nombra, que le dirige, que le orienta, que le asigna un espacio, un tiempo, un código, una conducta.

Las implicaciones curriculares relacionadas con el género han sido estudiadas desde diferentes tópicos y por diferentes investigadores. Rodríguez (2010) menciona algunos de los frentes donde se observan estas prácticas: los libros de texto, el lenguaje escolar, el trato entre chicos y chicas en las instituciones educativas, sus valores, los modelos de masculinidad y feminidad, las relaciones de dominación, la competencia académica de hombres y mujeres, la violencia escolar.

\subsection{EL JUEGO SE CURRICULARIZA Y SE INTEGRA A LA CULTURA ESCOLAR Y A LA CULTURA DE LA CIUDAD}

En este acápite, nos interesamos por la relación entre currículo y juego y por el lugar que la práctica jugada posee en la cultura ciudadana. Se atiende, además, la necesidad de una definición de los JRTC, lo cual implica una aproximación a nociones que, de una u otra manera, tocan semánticamente con lo que el juego abarca; estamos hablando de las nociones de juego tradicional, juego popular, juego autóctono, juego de la calle y recreación.

\subsubsection{El juego}

Varias ciencias y disciplinas sociales se han dedicado a este tema, ha sido estudiado por muchos autores que desde campos diversos aportan nuevos marcos explicativos. Las definiciones clásicas de Huizinga y Caillois siguen iluminado buena parte de los estudios que se emprenden sobre esta práctica social tan sensible a lo humano. En Homo Ludens, Huizinga define el juego como "Una acción u ocupación libre, que se desarrolla dentro de unos límites espaciales y temporales determinados, según reglas absolutamente obligatorias, aunque libremente aceptadas, acción que tiene su fin en sí misma y [que] va acompañada de un sentimiento de tensión y alegría y de la consciencia de ser de otro modo que en la vida corriente" (Huizinga, 1972: 43-44). Por su parte, Caillois sostiene que el juego es "una actividad libre y voluntaria [...] fuente de alegría y diversión" (1986: 31 ); este segundo pensador agrega que el juego es una actividad caracterizada por ser libre, separada, incierta, improductiva, reglamentada y ficticia. 


\subsubsection{Juego tradicional, Juego autóctono y juego popular}

Trigueros (2000) reconoce que es habitual que se confundan términos como juego tradicional, juego popular, juego autóctono y juego folclórico; ella encuentra que se utilizan indistintamente. De hecho, a partir de nuestro rastreo, cartografiando las formas de juego, podemos afirmar que estas prácticas jugadas guardan similitudes, comportan relaciones en su configuración histórica y cultural. Esto implica un proceso de precisión terminológica: acompañar la palabra juego con lo tradicional representa una adjetivación "que viene a indicar lo que es de uso común, usual y que implica repetición de base a la costumbre adquirida" (Lavega y Olaso, 2003: 12). Para estos investigadores, "hacer referencia a la tradición implica [la] transmisión de hechos históricos, [de] leyes y composiciones literarias [...] de generación en generación. Se trata, en definitiva, de transmitir costumbres y hábitos establecidos por los hombres de una misma comunidad" (13).

Los juegos populares son aquellos que son conocidos, compartidos y practicados por muchas personas en el mundo (saltar la cuerda) y que se diferencian de los juegos autóctonos porque estos últimos tienen sus raíces o nacen en un determinado lugar, en este caso se subraya el origen del juego, su pertenencia geográfica (Véase Gráfica 1).

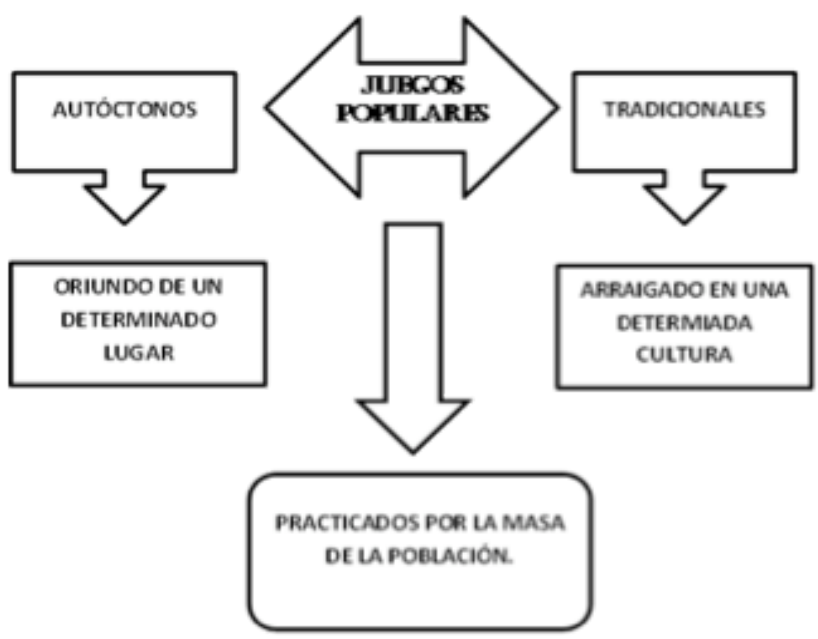

Gráfica 1. Juegos populares, autóctonos y tradicionales (Rebollo, 2002: 32) 
Gómez (2009), definiendo los JRTC, destaca que no son una creación autóctona; los reconoce como un evento que reúne un conjunto de prácticas (trompo, yoyo, carro de rodillos, cuerda, canicas, etc.) que son patrimonio universal y que, a fuerza de una apropiación sin fronteras, pierden su asignación local. Se trata de prácticas que son modificadas y singularizadas cuando son retomadas y recreadas por las localidades. Los JRTC pertenecen al acervo cultural caldeño, constituyen "una alternativa de recreación popular y un medio eficaz para el logro del desarrollo educativo, social y psicomotriz" (Gómez, 2009: 53). La adjetivación callejera significa que, en el origen de los juegos, "[...] fue la calle el escenario central de su nacimiento, realización y evolución a través de las diferentes etnias de la humanidad" (53).

\section{METODOLOGÍA}

Dada la problematización de los JRTC, este estudio opta por la ruta cualitativa. Reese, Kroesen y Gallimore (2000) plantean que la manera como está formulada la pregunta de investigación determina en gran medida el método a utilizar. Para responder a una pregunta de investigación, relacionada con las representaciones sociales sobre inclusión de género y sexo que posee el estudiantado participante en los JRTC, se optó por una investigación cualitativa con enfoque etnográfico. La condición de observador participante del investigador y el hecho de ser integrante de la cultura escolar caldeña, fueron factores que también orientaron esta elección. Esta etnografía privilegia la voz del estudiantado y tiene en cuenta que la unidad de análisis u objeto específico de estudio es la realidad que emerge de la interacción social jugada (mediada por las categorías de género y sexo).

La fuente primaria se constituye a partir de la información entregada por veinticuatro estudiantes de los grados noveno, décimo y once de seis instituciones educativas públicas del municipio de Caldas. Esta selección se realizó acudiendo a la técnica de Polit y Hungler (2000) que consiste en pedir a los informantes que recomienden a otros posibles informadores. En la investigación sobre los JRTC estos nuevos participantes fueron informantes claves.

A propósito de las técnicas para recolectar la información, Brisett (1996: 2) plantea que las fotografías son "artefactos socialmente construidos que nos cuentan algo sobre la

\begin{tabular}{|c|c|}
\hline \multicolumn{2}{|c|}{ Criterios de selección de la muestra } \\
\hline Instituciones educativas & Estudiantado \\
\hline Pertenecientes al municipio de Caldas. & Matriculado en institución educativa de Caldas. \\
\hline Públicas o privadas. & De los grados 9, 10 y 11. \\
\hline Urbanas y rurales. & Habitantes de Caldas. \\
\hline De secundaria. & Participantes en los JRTC en los últimos 3 \\
años.
\end{tabular}

Cuadro 1. Criterios de selección de la muestra 
cultura reflejada". Por su parte, Moreno (2012) puntualiza el valor que posee la fotografía para documentar, describir y comprender la cultura escolar estudiada e ir más allá de los signos visibles. El estudio privilegió este recurso como medio para recabar información directa e indirecta. A cada uno de los estudiantes seleccionados se le asignó la tarea de hacer treinta registros fotográficos durante el desarrollo de los JRTC. En este estudio se practicó la foto-discusión, técnica que consiste en una conversación que realiza el investigador con grupos selectos de la población investigada. El investigador, luego de recibir las fotografías realizadas por los estudiantes, hace una codificación inductiva dictada por las propias imágenes y con ella organiza una presentación temática fotográfica que orienta la conversación. Se considera el valor de la foto como referencia mediática que entrega información directa desde la imagen y como medio que tiene el potencial de provocar discurso desde composiciones seriadas del investigador; permitiéndose así la posibilidad de generar una evocación de gran valor comprensivo de las representaciones sociales situadas.

Desde la primera aproximación analítica a los discursos de género y sexo del estudiantado, ya en el proceso de triangulación, emerge inductivamente una matriz de análisis, que es también un resultado de la conversación entre las categorías nativas, las categorías de los expertos y las categorías del investigador. Esta matriz, (expuesta en la Gráfica 2) permitió un análisis en profundidad de los discursos que entregaron los estudiantes investigados en las foto-discusiones.

Dicha matriz está compuesta por dos ejes (X e Y); el eje de las X contiene los orientadores de designación (rol de género, estereotipo de género y sexo) y el concepto de representación social; el eje de las Y, por su parte, incluye los tipos de designación (autodesignaciones, heterodesignaciones y la inclusión/ exclusión institucional).

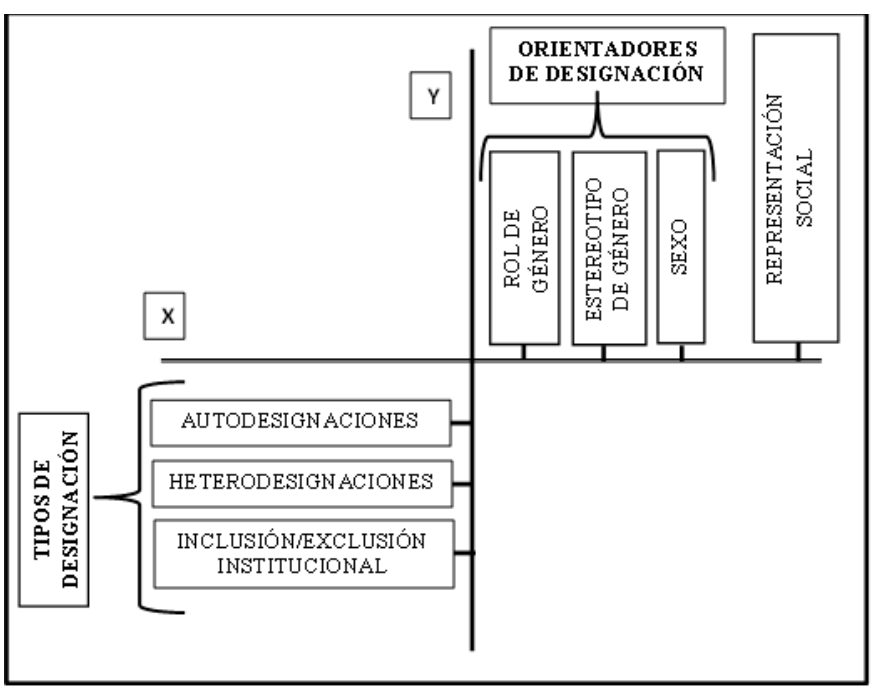

Gráfica 2. Matriz de análisis de los discursos de género y sexo en los JRTC 


\section{RESULTADOS Y DISCUSIÓN}

\subsection{AUTODESIGNACIÓN DEL HOMBRE: UN ASUNTO DE FUERZA}

Los jóvenes en el discurso sobre los JRTC se autodesignan de manera incluyente, eso es lo que parece prevalecer. Para ellos no hay espacio, tiempo y actividad de Juegos en el que no puedan participar. El sentido que poseen de su dotación biofísica (fuertes, resistentes, rápidos) con énfasis en la capacidad condicional de la fuerza (capacidad que ellos masculinizan) parece que les confiere su orientación dominativa en los Juegos; dominio o dominación que se ve favorecida por un diseño de JRTC con una alta enmarcación competitiva a la manera de los deportes tradicionales. Priman el metro, el cronómetro, la distancia, la planilla, la pirámide selectiva que favorecen a los más fuertes. Las autodesignaciones de los jóvenes que aparecen como hegemónicas, dado el marco social de dominancia patriarcal y androcéntrica que parecen prevalecer en las relaciones entre los y las caldeñas no se manifiestan explícitamente, pero al leer transversalmente algunos de estos discursos se deja ver tal dominancia en forma implícita; un estudiante comenta que:

“...uno ve a las mujeres y siempre se les ve el intento y la fuerza [...] pero, la capacidad no es la misma [...]" (Daniel, 15 años, FD: 2). ${ }^{6}$

En la misma dirección, al referirse a la participación de la mujer en la vara de premio, otro estudiante dice:

“[...] de pronto sería como más difícil para una mujer [subir a la vara], pues no es imposible, pero para ellas es como más bien las rondas" (Julio, 18 años, FD: 3).

Estos planteamientos de los estudiantes pueden leerse en clave de la marginación de la mujer bajo el argumento de lo biofísico; con relación a esto, Nogués (2003), ubica posibles causas de la marginación de las mujeres, expone la fuerza física como una de las cuatro principales causales de dicha marginación; las otras tres son: la agresividad y la violencia psíquica, el confinamiento reproductor y el desprecio por la diferencia. Según él, la predominancia de la fuerza masculina es incuestionable, la transferencia de esta diferencia biológica en roles muy concretos de dominación masculina estará facilitada por aquel ambiente social donde en la actividad económica prima la fuerza, ya sea como mecanismo o como argumento. Si los JRTC promueven ambientes de competición, donde el ganar o el perder se definen por la fuerza, el sentido y la práctica de la dominancia masculina, en Caldas será inevitable. Dicen los jóvenes estudiantes que ellas tienen más habilidad para la realización de juegos en los que la fuerza no es la actividad predominante, sin embargo, en sus autodesignaciones, este hecho no los excluye de la participación en este tipo de prácticas asignadas por ellos mismos a las mujeres. Los estudiantes van incursionando en prácticas de las que ellos antes se autoexcluían. Y esto puede entenderse como apropiación progresiva de nuevas prácticas; al respecto también dice:

"[...] ahora, allí se van viendo a los hombres practicar esos deportes, esos juegos, como por ejemplo el catapiz [...] se han visto ya muchos hombres practicando catapiz en los últimos años, también en la golosa o saltando laso" (Víctor, 17 años FD: 4).

$6 \quad$ FD1, FD2, FD3, FD4: Se refieren a la foto-discusión en la que participaron los estudiantes. 


\subsection{AUTODESIGNACIÓN DE LA MUJER: EN EL HARÉN PEDAGÓGICO, ENTRE LA INVISIBILIDAD Y EL EMPODERAMIENTO}

A diferencia de los jóvenes, las autodesignaciones de las jóvenes están de manera explícita en sus voces. En el análisis de los discursos del estudiantado se evidencian dos tipos de autodesignaciones en las jóvenes; la primera excluyente y la segunda incluyente. En la primera, bajo el argumento de "no tener similitudes biológicas con los hombres" en cuanto a la fuerza, ellas dejan ver un prejuicio que anula su participación por autodesignación. Ellas dicen que no pueden participar en igualdad de condiciones y por ello tienden a autoexcluirse y a apostarle a prácticas en las que predomina lo femenino, bien sea en el juego o en el juguete feminizado. En este estudio se escucharon voces que dan cuenta de la autodesignación femenina excluyente, tal es el caso de María Fernanda, Estefanía y Natalia. Ellas esgrimen las siguientes razones:

“[...] porque para una mujer es como mucho más difícil subir [vara de premio], pues uno piensa que para una mujer es mucho más difícil hacer ese esfuerzo y llegar hasta allá arriba que si lo hiciera un hombre" (María Fernanda, 15 años, FD: 1).

"La mujer se destaca por lo femenina, si me entiende [...] y una mujer, en una vara de premio, sacando músculos y haciendo esas fuerzas que hace un hombre [...] ino se ve!" (Estefanía, 17 años FD: 2).

"[...] si, se ve rara, sinceramente se ve muy rara [...] puede hacer algo, pero un poco más delicado" (Natalia, 15 años, FD: 2).

“... es que mire lo que muestra la foto [habla frente a una foto de las niñas haciendo el ensayo final para la ronda en el parque, [ver foto 1] las mujeres por lo femenina y por lo sexy [consintiendo con su gesto] y todo eso... dígame... una mujer montada en una vara de premio, cómo se va a ver... como un machito, como un hombre” (Estefanía, 17 años, FD: 2).

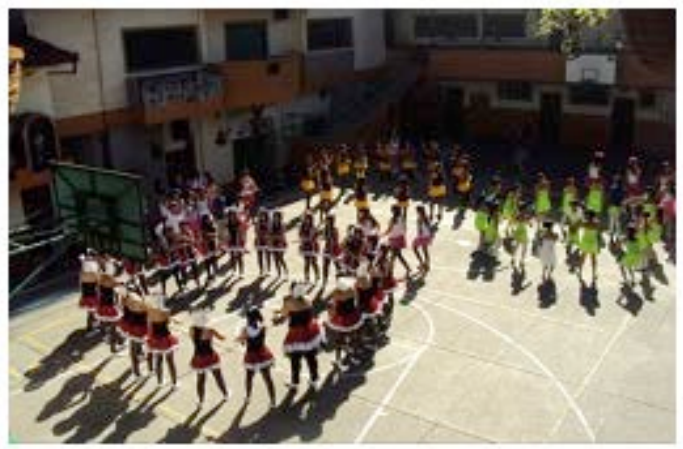

Foto 1. Ensayando. Tomada por Sebastián (16 años) 
Estas voces femeninas dejan ver que la autodesignación excluyente habita en las representaciones de las jóvenes estudiantes caldeñas; sus creencias manifiestas dan cuenta como en algunas prácticas de JRTC la mujer, caso vara de premio o carro de rodillos, se autoexcluye al sentirse débil, rara y machita; más adelante podremos analizar cómo esta representación conecta con la heterodesignación excluyente de los hombres. Ellos en la vara de premio las ven raras y ellas así se lo creen. Esta rareza gana espacio en la representación social compartida sobre quién, cómo y bajo qué motivaciones se puede subir a la vara. Una investigación hecha con grupos de discusión con adolescentes de la misma edad de la población de este estudio, realizada por Ezzatti (2009), arrojó información coincidente; un sector significativo de las jóvenes señaló que para ser femenina se debe ser sutil, delicada y que las mujeres deben resaltar sus atributos de belleza por medio de la ropa o del maquillaje. Ello demuestra que la estigmatización femenina está socialmente naturalizada, pero también muestra la manera como tempranamente opera la autoexclusión desde ellas mismas. Por su parte, Santos (2000) reconoce, en este tipo de situaciones, la pervivencia en las escolares de una falta de confianza en sí mismas. Ellas, asistiendo a prácticas donde prevalece la participación de los varones, piensan que no van a tener la posibilidad de imponerse.

La sustentación de tales prácticas en la fuerza (característica atribuida a los varones), define una cultura en la que está imbuido el pensamiento de muchos hombres y también el pensamiento de muchas mujeres; mujeres que terminan por autodesignarse excluidas y por ello candidatas a conformar lo que Ball (Cit. en Santos, 2000: 61) denomina como "harenes pedagógicos". En su autodesignación excluyente, sugiere este investigador, en la clase, en el juego, en el torneo, en la institución, en los Juegos, quedan a merced de un varón sacralizado por las mismas mujeres en su claudicación.

En el segundo tipo de autodesignación (incluyente), ellas, venciendo el prejuicio social presente en las representaciones de un sector significativo de las mujeres -prejuicio que las excluye de su presencia en lo social-, se empoderan y aparecen como sujetos. Más que como sujetos sujetados, como sujetos emancipados que reclaman su lugar en el espacio de todos y de todas, espacio que es mucho más de lo que ellas han tenido históricamente. A ella se le asignó un espacio, el adentro y al hombre, el afuera (Garcés, 2002). La autodesignación femenina incluyente da a la mujer un lugar en el espacio social, pero no uno en el espacio para las mujeres. En las siguientes voces se pueden leer manifestaciones de las mujeres participantes reclamando su derecho como ciudadanas, admitiendo la diferencia inevitable, pero luchando por la igualdad obligatoria en cuanto a oportunidades, sin dejar de ser (dicen ellas) sexis, delicadas ni femeninas. Ellas exponen:

“[...] pero no solo en esos juegos; por ejemplo, me pongo a mirar en mi experiencia en carro de rodillos, yo quedé en segundo lugar... hay unas mujeres que vienen muy bien preparadas en su físico y a pesar de eso no dejan la feminidad para ser masculinas, no la dejan... pues seguimos siendo femeninas, practicamos un deporte que nos exige más y tiene más fuerza y no por eso dejamos de ser en sí mujeres [no dejamos] de ser más femeninas y así" (Diana Patricia, 15 años, FD: 4).

A continuación ella misma manifiesta:

"[...] no es sólo diferenciarnos por la fuerza [...] en los juegos de la calle en realidad son muchas las mujeres que pueden subirse en una vara de premio, también podemos correr un carro de rodillos y no sólo identificarnos por eso, si no por la persona que se es, porque las mujeres también podemos participar en muchos deportes a fuerza, ya depende de la persona 
que sí se sienta fuerte para eso, si tiene las capacidades para esto o para lo otro" (Diana Patricia, 15 años FD: 4).

Otra estudiante refuerza el anterior planteamiento:

"Yo considero que la mujer puede también hacer cosas de fuerza, igual que el hombre también puede hacer las rondas, también puede involucrarse en eso, no me perece pues que deberíamos diferenciarlos" (Daniela, 16 años, FD: 4).

Según Ramírez et al. (2008), la territorialización implica unas relaciones de poder dadas por el grado de dominio que tienen unas personas con relación a otras en sus espacios de actuación. Según esto, en los discursos se podrían valorar las relaciones de poder y las relaciones de dominación. Resuenan las palabras de Diana y Daniela, en sus tonos de voz y en el sentido de sus discursos, se lee como ellas, jugando, van conquistando un lugar. Los JRTC define un territorio que también les pertenece; ellas no son invitadas de piedra, hacen parte fundante del paisaje de Juegos. Nogués (2004) nos recuerda que los movimientos feministas valoran la recuperación de la palabra como paso imprescindible para recuperar la igualdad y estas jóvenes, en los JRTC, tienen palabra y con ello un lugar en la acción. Hay voces dentro de las mismas estudiantes que parecen querer explicar las condiciones de posibilidad de la autodesignación incluyente y de la autodesignación excluyente desde la reproducción cultural. Tempranamente, se crea una brecha entre la cultura jugada y el juguete de los niños, y entre la cultura jugada y el juguete de las niñas; para ellos, los carritos, los caballitos, el balón, el carro de rodillos, el trompo, la perinola y para ellas, la muñeca, las cocinitas, las rondas, el baile, la gimnasia, el catapiz. Con esto, dos chicas estudiantes participantes en los Juegos argumentan que:

"A mí me parece que cada uno se caracteriza por su... cómo le digo, mmm, por su físico, entonces uno no puede comparar su físico con alguien que siempre ha crecido jugando con niños a alguien que siempre ha estado con niñas. Si desde siempre estuviéramos los niños y las niñas jugando lo mismo de pronto se podría, pero es que desde pequeño siempre las niñas con las niñas y los niños con los niños" (Natalia, 15 años, FD: 2).

"[...] desde pequeñas las niñas con barbies y no sé que y los niños son con carros, con balones" (Estefanía, 17 años, FD: 2).

Es evidente como ante nuestros ojos, en la experiencia cotidiana de la juventud en los espacios educativo-deportivos, se puede estar constituyendo -sobre la base de la diferencia sexual- una división sexual, una institución de la desigualdad y las jerarquías, una cultura sexista. 


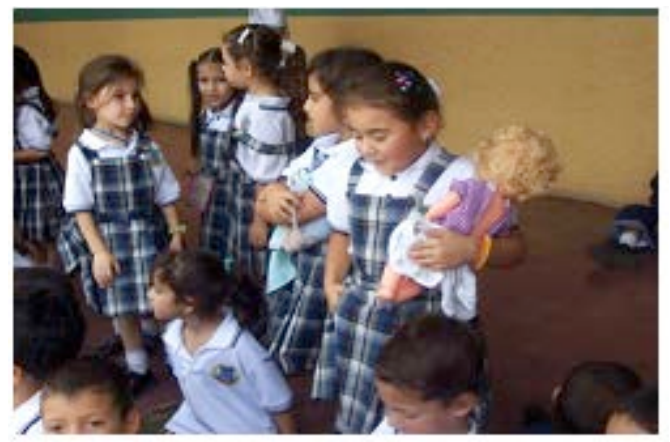

Foto 2. Interiorizando un rol. Archivo PES

Desde las instancias de socialización o vivienda (escuela, casa, los JRTC), se produce tempranamente una diferenciación entre hombres y mujeres, personas que aún sin nacer ya están predestinadas a tal diferenciación. Es posible que "casi sin darnos cuenta se asignen unos determinados comportamientos que se van interiorizando y asumiendo hasta el punto que hay quienes los consideran tan naturales, tan propios de cada uno de los sexos que se piensa que vienen determinados genéticamente" (Moreno, 2000: 14).

\subsection{LA HETERODESIGNACIÓN DEL HOMBRE: JUNTOS PERO NO REVUELTOS}

Como se había mencionado anteriormente, los hombres demuestran en el estudio autodesignaciones incluyentes. Este tipo de autodesignaciones están acompañadas por múltiples heterodesignaciones excluyentes con respecto a la mujer. En el estudio no se evidencian heterodesignaciones excluyentes entre los mismos sexos, las que también se presentan en este tipo de espacios de disputa de poder. Las heterodesignaciones de los hombres excluyentes están mediadas por tres orientadores de designación (1) los roles de género (juguete y capacidad física), (2) por los estereotipos de género (competencia y estética) y (3) por el sexo como determinante biológico.

\subsection{LA HETERODESIGNACIÓN EXCLUYENTE DEL HOMBRE POR EL JUGUETE}

El juego y el juguete están influenciados por la cultura y el entorno donde se despliegan (Martínez y Vélez, 2008). Desde la cultura familiar y escolar se asignan en forma directa o con sutilezas adultas, juegos y juguetes para niños y juegos y juguetes para niñas. Desde la familia, la escuela y el deporte se ha favorecido la utilización de un juguete determinado por forma, color, uso proyectado y condición en lo social desde un acumulado histórico constituido en las relaciones de género. Hay adultos que permiten o no jugar a los niños y niñas con determinados juguetes. La escuela tradicional refuerza esta cultura sexista en torno al juguete marcado y al juego sexista. Cuando se está en las fases iniciales de los JRTC se comienza a notar una cultura profesoral que favorece un tipo de juego en función del sexo y en los chicos y chicas una preferencia por determinados juegos y formas de jugar. Se evidencia en las expresiones de los estudiantes una continuidad entre la cultura familiar, escolar y la de JRTC. En algunos estudiantes se 
deja ver tempranamente el sesgo de este acumulado cultural, sesgo del que muy pocos escapan. En tal sentido, un estudiante dice que:

"[...] las mujeres practican las rondas, catapiz, golosa y saltos; los hombres más que todo utilizan es la fuerza para los carros de rodillos, vara de premio, trompo, etc." (Víctor, 17 años, $F D: 4)$.

En las palabras de Sebastián se evidencia que algunos de ellos son conscientes del peso de la cultura con relación al asunto del juguete marcado por el género, para él:

"Según la tradición se ha formado que son los hombres quienes se montan a la vara de premios" (Sebastián, 16 años, FD: 1).

Víctor y Sebastián son contundentes; para ellos no hay concesión, no dan razones para una práctica coeducativa. La separación tomó cuerpo en su experiencia familiar y escolar; ante la inquietud sobre la posibilidad (imaginario) de un juego integrado, responden respectivamente:

"Es mejor [los juegos] para hombres y las peladas aparte" (Sebastián, 16 años, FD: 1).

"Más bien ¿por qué no separarlos? o hacer juegos para cada uno [Para ellos y para ellas por separado]" (Víctor, 17 años, FD: 4).

Parece que en los JRTC la práctica de las rondas, donde la mujer aparece como dominante, está ganado espacio con relación a los otros juegos. Este hecho puede estar siendo favorecido, tanto por el interés de las y los participantes, como por el interés del público. Esto puede ser una salida de las mujeres ante la heterodesignación excluyente de los hombres que se ejerce en las otras prácticas. ${ }^{7}$ Hay prácticas de predominancia en los jóvenes como el trompo, el carro de rodillos, donde parece que ellas hacen una incursión tímida, ya que la heterodesignación excluyente de los hombres las estigmatiza y para ellos se pierde su armonía, delicadeza y feminidad. Esto se evidencia en los siguientes discursos:

"[...] porque las mujeres casi nunca se han visto participar en esos juegos [trompo, vara de premio] en cambio los hombres sí y si una mujer entra a ese juego se ve muy raro ihuy! esta mujer tan marimacha, le pueden decir así” (Robinson, 15 años, FD: 4).

“y uno puede pensar ¿y esa marimacha montada allá qué?” (Robinson, 15 años, FD: 4).

“[...] si, es que una mujer en una vara de premios se vería muy fea” (Daniel, 15 años, FD: 2).

“ [a] una dama [se] la reconoce más como por su cariño y su delicadeza, en cambio nosotros nos dejamos llevar por algo muy aparte, entonces cuando vemos a una niña realizando eso [subir a la vara de premio] no la vemos de la misma manera, la vemos como con otra visión, con otros ojos... es como cuando ves a una mujer manejando una XTZ que es una moto demasiado grande, la ves con admiración, pero a la vez con ese... no le ves como su delicadeza" (Edwin, 15 años, FD: 4).

7 Hay una investigación de Chepyator-Thomson y Ennis de 1997 (Cit. en Devís y Fuentes, 2005), en la que encuentran que los alumnos estadounidenses de secundaria reproducen formas tradicionalmente dominantes de masculinidad y de feminidad a la hora de seleccionar y de participar en actividades físicas; no es gratuito el interés de participación en una u otra actividad por ellos o ellas. 
Esta heterodesignación excluyente de los jóvenes está conectada con la pervivencia de la imagen social de la masculinidad y la feminidad sobre viejos cánones hegemónicos. Plantea Ezzatti (2009) que las jóvenes vienen de un hogar donde se plantea un deber ser femenino; en este caso, ellas llegan a los Juegos, trepan la vara y a ellos se les cae el mundo: "allí está la marimacha". Instituciones como la familia y la escuela hacen poco por cerrar esa profunda brecha. Si de lo que se trata es de estimular formativamente la constitución de espacios para la superación de los lastres culturales -que se imponen en las relaciones entre los hombres y las mujeres-, los juguetes no deberían limitar, por sí mismos -en función de una condición de género asignada-, quién juega con qué. En esta dirección, se coincide en esta investigación con una de las conclusiones del estudio desarrollado con niños mexicanos por Martínez y Vélez (2008); los juguetes en sí mismos no tienen género, es la cultura y la sociedad quien los etiqueta para un sexo u otro.

\subsection{HETERODESIGNACIÓN EXCLUYENTE DEL HOMBRE POR LA CAPACIDAD FÍSICA}

La capacidad física está conectada entre el estudiantado con la masculinidad y la hombría. En los Juegos se evidencia claramente la masculinización de estas capacidades. El valor de la fuerza física y en general, el valor de las capacidades condicionales (la fuerza, la resistencia, la velocidad), son expresiones asociadas a la dominancia masculina. En el juego, ellas tienen mayor presencia y aceptación en aquellas prácticas que demandan habilidades muy específicas o que requieren de capacidades perceptivas motrices. En el medio deportivo parece que a fuerza del reclamo social por la equidad de género, la brecha se va cerrando. En los Juegos entre el estudiantado, se conservan ciertas creencias que matizan la fuerza como una capacidad propia de lo masculino; igual pasa con factores como la agresividad, la combatividad o la garra. Desde una perspectiva de rol de género, naturalizando la capacidad física, asociando fuerza/brutalidad al rol masculino y asociando la delicadeza a lo femenino, un estudiante plantea que los hombres:

"[...] somos como más bruscos, tenemos una tendencia a realizar las cosas con más fuerza; se puede decir que somos más brutos, en cambio ellas son más delicadas” (Edwin, 15 años, $F D: 4)$.

Otro joven expone:

"Como son mujeres, deberían estar en un nivel más bajo, menos duro. Una mujer no va a subir hasta por allá [a la vara de premio], para ellas debe [ser] más suave. Sí, son capaces, no se pone en duda, pero no como para tirarles tan duro" (Julio, 18 años, FD: 3).

4.6.1 Por el hecho de ser mujer: en las voces del estudiantado de los Juegos se manifiestan otras heterodesignaciones excluyentes, ya sea por razones de sexo o por el nivel de competencia. La primera razón argumenta lo biológico como factor de exclusión; la segunda, está relacionada con una exclusión en función de la capacidad competitiva. Ellos, como se verá más adelante, se consideran Goliat y lo máximo que le conceden a ellas es ser David (ellos admiten que pueden presentarse sorpresas). Estos dos factores tienen que ver con el hecho de que lo humano occidental históricamente solo ha contemplado la experiencia masculina del mundo, en el que incluye a las mujeres como 
seres subsidiarios. Ellas ocupan lo otro inferior, complementario o subordinado. Según Oliveira (2000), se estaría evidenciando en este tipo de concepciones una violencia que se manifiesta de modo muy diverso y que a menudo se desplaza espectralmente por todas las formas de discriminación y dominación, pasando desde una exclusión sutil hasta una exclusión brutal. Con relación al sexo como factor de heterodesignación excluyente por parte de los hombres, dicen dos estudiantes que:

"Si ponemos unas personas mujeres a competir con hombres no van a... usted sabe que por naturaleza la mujer, cierto... no va a responder igual que el hombre, entonces tendría como una... no sé... una contrariedad" (Sebastián, 16 años, FD: 1).

“[...] por naturaleza las mujeres no rinden más que los hombres” (Robinson, 15 años, FD: 4).

Lwontin y otros, 1987 (Cit. en Santos, 2000), insisten en que el determinismo biológico ha sido un refugio conservador; denuncian que hay una trama generada por la cultura entorno al género. En el caso que nos convoca en este aparte, se evidencia como la heterodesignación excluyente está claramente definida por la cultura. Hay formas de vivir y de relacionarnos como hombres y mujeres que hacen que los estudiantes piensen que las mujeres no pueden ser exitosas en la competición con los hombres. Esta creencia estereotípica será definitiva para el futuro adulto de las relaciones. Socialmente, se reproduce la idea que lleva a una identificación del cuerpo femenino con el ámbito íntimo y privado, la crianza, la reproducción, la fragilidad, con el adentro. Condicionados, recuerda Varela (1997), las histerizamos: ninfómanas, asustadizas, inquietas, inestables y frágiles; creencias que refuerzan las condiciones de exclusión y las muestran como menos competitivas a los ojos de los hombres y de la sociedad, situación que se ve reforzada por los cánones competitivos diferenciales que se asignan culturalmente al hombre y a la mujer.

4.6.2 Por la competencia: en cuanto a la competencia que se da en los Juegos, Daniel, dando muestra de un tipo de heterodesignación excluyente desde los estudiantes plantea la siguiente relación:

"Cuando yo llego a una competencia tengo que ser siempre Goliat y los otros son David, yo tengo que ser Goliat para ganar, entonces cuando una mujer va a competir contra un hombre, un hombre nunca se debe relajar y una mujer nunca decir !ahhh no ; yo ya perdí" (Daniel, 15 años, FD: 2).

Ellos admiten que ellas pueden entrar en disputa con el hombre, pero siempre desde una condición inferior, de todas maneras, dirían, ella es menos.

\subsection{LA HETERODESIGNACIÓN INCLUYENTE DEL HOMBRE: NOSOTROS TAMBIÉN JUGAMOS GOLOSA}

Para los hombres no es "vengan, mujeres, a jugar los juegos de hombres"; es un... "mujeres, nosotros vamos a jugar sus juegos". En los discursos analizados, se observa una relación directa entre las heterodesignaciones excluyentes y la baja frecuencia de heterodesignaciones incluyentes que se presentan en los hombres. Esta evidencia podría estar conectada directamente con el arraigo de las prácticas sexistas en el juego a estas edades. Esta situación se deja ver en las clases de educación física cuando el profesor invita a formar subgrupos. La respuesta organizativa del estudiantado es inmediata y rápida para no quedar out, inmediatamente aparecen los grupos organizados por el mismo sexo, 
nadie quiere que se llame a confusiones (...). En el caso de los JRTC, en los talleres previos de construcción del juguete, cuando se invita a una organización subgrupal de trabajo, aparece la misma respuesta y es sólo a partir de las consignas directivas del profesor cuando, a regañadientes, se logran (a veces) grupos de trabajo compuestos por niños y niñas. Las excepciones están dadas por lazos de amistad previos o externos a la condición escolar. Como muestras de heterodesiganaciones incluyentes de los hombres se pueden observar:

"Hay juegos en los que se utilizan los dos sexos, es como en las rondas, porque ahí pueden participar hombres y mujeres. Hay juegos que son más que todo para mujeres, también se han visto los hombres practicando ese deporte o juegos, como por ejemplo el catapiz. Ya se han visto hombres practicando catapiz en los últimos años, también se les ve en la golosa y saltando el lazo [...]" (Víctor, 17 años, FD: 4).

Este discurso muestra la pedagogización que podría estarse presentando con relación al asunto. El hecho que hombres y mujeres acudan a una misma práctica jugada o a un mismo ejercicio, puede estar dado por la voluntad coeducativa que surge del proceso de sensibilización escolar, pero también puede obedecer a un proceso de didactización que se agota una vez suena la campana. Se observa en la expresión del estudiante una manera de hacer parte del juego por obligatoriedad, porque le está permitido escolarmente. Esto sería una coeducación incluyente forzada. Hay una diferencia significativa entre una inclusión sentida y una inclusión por norma escolar. En la observación que hace Víctor parece que el jugar juntos a una misma cosa por parte de los jóvenes empieza a ser algo propio del paisaje institucional formal. Víctor narra la experiencia de una chica ejemplar que se prepara para mejorar sus tiempos en una competencia con hombres:

"Me imagino que la chica ha ido practicando durante todo el año para superar el tiempo de los hombres, para demostrarle a las mujeres que si son capaces de todo, más que todo de fuerza" (Víctor, 17 años, FD: 4).

El hombre, en este caso, es referente de competición, pero no de dominación; es un par en competencia al que se le puede ganar.

Para un mejor entendimiento de las autodesignaciones y heterodesignaciones (incluyentes y excluyentes) de hombres y mujeres en los JRTC, se presenta la siguiente Ilustración 1. 


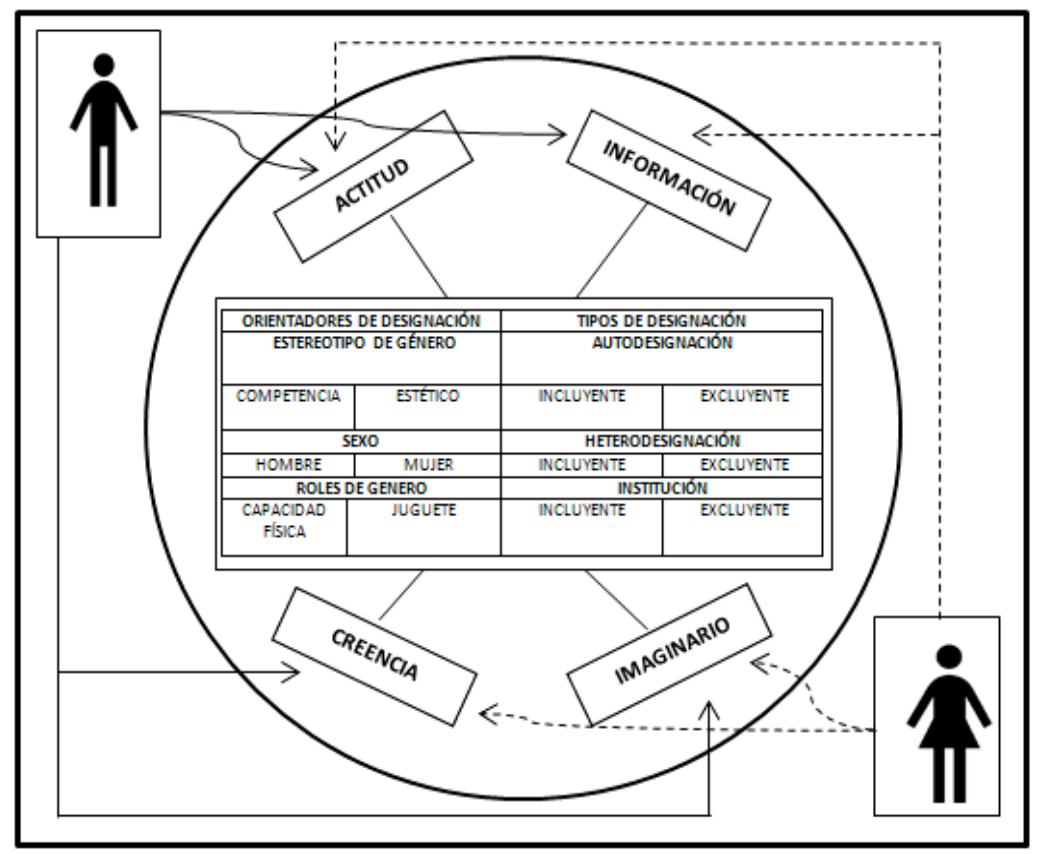

Ilustración 1. Representaciones sociales de género y sexo en los JRTC

\section{CONCLUSIONES}

Los JRTC son una actividad en la que participan hombres y mujeres. Durante cada una de las fases de los Juegos, ambos se encuentran alrededor del juego tradicional; hacen preparativos intramurales, desfilan ante el pueblo, cantan el himno nacional, juran juego limpio, tiran trompo, empujan carros de rodillos, saltan la cuerda, trepan la vara. Pero, debajo de toda esta armonía, se mueven fuerzas, intereses, dominaciones y exclusiones sutiles.

En los estudiantes que participan en los Juegos sigue primando una cultura andro $\neg$ céntrica. Los JRTC prevalentemente están representados por los hombres como juegos para ellos. Para ellas, las rondas, la golosa, las cuerdas y el catapiz (los juegos de prevalencia perceptivo-motriz). Para ellos, el carro de rodillos, la vara de premio, el trompo y las canicas (los juegos de prevalencia condicional). No obstante, se constata también que ellos, más que ellas, se autorizan a participar en todos los juegos.

En las seis instituciones investigadas se hacen esfuerzos por contrarrestar los efectos negativos de la cultura androcéntrica; en el conjunto de las interacciones social-educativas escolares se observan contenidos curriculares sobre la equidad de género, educación sexual, entre otros; contenidos abordados a través de campañas lúdicas, carteleras, boletines, actos cívicos, etc. A pesar de ello, sigue en cuestión el tipo de estrategias que las instituciones educativas despliegan para superar este fenómeno social; parece que la escolarización y 
allí la estrategia los JRTC no ha logrado concretar aún el deber ser sobre la relación de género y sexo predicado en los proyectos coeducativos.

En los JRTC, las autodesignaciones de las estudiantes están presentes a manera de exclusión y de inclusión. Ellas, desde las representaciones hegemónicas de los hombres -quienes las ven con limitaciones para participar en algunos juegos- se han adaptado a creencias que favorecen la exclusión de la mujer. Sin embargo, paradójicamente, algunas mujeres "raras" que se mueven en los márgenes, escapan a estos cánones y terminan en contravía con los estereotipos asignados a las mujeres socialmente.

Existen, en los Juegos, varios orientadores de designación que provocan, en el discurso de los hombres, heterodesignaciones excluyentes; los juguetes, la capacidad motriz, el sexo y la competencia se dejan ver como cuestiones neurálgicas con las cuales los hombres precisan la exclusión.

En los Juegos no se presentan heterodesignaciones excluyentes hacia los hombres; en sus discursos, ellos y ellas dan a entender que la participación del hombre es una obviedad, dada y naturalizada. Por ello, no se pone en cuestión su participación. Esto se corresponde con una cultura escolar donde el androcentrismo y la cultura patriarcal siguen vigentes.

Con alguna frecuencia se presentan heterodesignaciones incluyentes en las mujeres. Por más que se quiera, aún en la cultura escolar, los JRTC siguen privilegiando la cultura masculina, invisibilizándose la cultura femenina. Ellas aún no se nombran; en sus discursos se nombran como "uno" o "unos" y no como "una" o "unas". El lenguaje anuncia claramente la pervivencia de la invisibilidad y la dominación.

Los Juegos, curricularizados en la educación física, podrían ser una herramienta práctica para superar el sexismo, desplazarían del currículo la influencia de los deportes tradicionales que son la base del currículo tradicional y que parecen favorecer, por su lógica constitutiva, el desarrollo de las actitudes sexistas; desde ellos la escuela estaría apostando por procesos de cambio en las interacciones entre la juventud, base para la transformación social real.

\section{REFERENCIAS BIBLIOGRÁFICAS}

Araya, S. (2002). Las representaciones sociales: Ejes teóricos para su discusión. Costa Rica: Leonardo Villegas.

Brisset, D. (1999). Acerca de la fotografía etnográfica. Gazeta de antropología, vol.15. Málaga. Consulta realizada en Marzo 10 de 2011. http://www.ugr.es/ pwlac/G15_11DemetrioE_Brisset_ Martin.pdf

Caillois, R. (1986). Los juegos y los hombres. La máscara y el vértigo. México: Colección popular.

Campillo, N. (2003). Ontología y diferencia de los sexos. En: S. Tubert, Del sexo al género. Los equívocos de un concepto (pp.83-120). Valencia: Ediciones Cátedra.

Devís, J. y Fuetes, J. (2005). ¿Qué permanece oculto del currículum oculto? Las identidades de género y de sexualidad en la educación física. Revista Iberoamericana de educación, vol. 39, 73-90.

Ezzatti, G. (2009). La imagen social de la femineidad y masculinidad en la enseñanza secundaria en Chile. Revista Educar, vol. n.35, 95-106.

Fernández, M. y Hernández, A. (2005). Las representaciones sociales: una forma de investigar la realidad educativa. Pedagogía y Saberes, vol. 23, 19-28. 
Garcés, A. (2002). Ser hombre/ser mujer Vidas separadas en Medellín, 1900-1940. Revista Universidad de Medellín, vol. 2, 142-166.

Gómez, H. (2009). Juegos recreativos tradicionales de la calle. Una herramienta pedagógica. Medellín: L. Vieco e Hijas Ltda.

Grinberg, S. y Levy, E. (2009). Pedagogía, currículo y subjetividad: entre pasado y futuro. Argentina: Universidad nacional de Quilmes.

Hall, S. (1997). Cultural representations signifying practices. London: Sage publications.

Hargreaves, A. (2000). A vueltas con la voz. Revista Kikiriki, vol. 42-43, 28-34.

Huizinga, J. (1972). Homo Ludens. Madrid: Alianza Editorial.

Jodelet, D. (1984). La representación social: fenómenos, concepto y teoría. En S. Moscivici, Psicología social II (pp. 469-494). Barcelona: Paidós.

Lavega, P. y Olaso, S. (2003). 1000 juegos y deportes populares y tradicionales. La tradición jugada. Barcelona: Service, S.L.

Martínez, M. y Vélez, M. (2008). Actitud en niños y adultos sobre los estereotipos de género en juguetes infantiles. Revista Ciencia ergo sum de México, vol. 2, 137-144.

Moreno, E. (2000). La transmisión de modelos sexistas en la escuela. En M. Santos Guerra, El harén pedagógico. (pp.11-30). Barcelona: Grao.

Moreno, W. (2010). La autonomía del maestro. En Instituto Ferrini. Medellín: Edita Instituto Ferrini, Colombia.

Moreno, W. (2012). Fotoetnografía e investigación en Educación Corporal: un giro en la mirada. En imprenta.

Moscovici, S. (1979). El psicoanálisis, su imagen y su público. Argentina: Huemul S.A.

Oliveira, M. (2000). La educación sentimental. Una carencia en el sistema educativo. En M. Santos Guerra, El harén pedagógico (pp.71-88). Barcelona: Grao.

Páramo, P. (2010). Las representaciones de género en profesores universitarios. Estudios pedagógicos, Vol. 36, n. 2, 177-193.

Polit, D y Hungler, B. (2000). Investigación científica en ciencias de la salud. México: Mc-Graw-Hill.

Ramírez, O.; Chacón, M. y Leiva, A. (2008). Descifrando los códigos de la cultura patriarcal en escuelas urbanas del sector oficial del norte del Huila. Entornos, vol. 21, 21-26.

Rebollo, J. (2002). Juegos Populares una propuesta para la escuela. Retos. Nuevas tendencias en Educación Física, deporte y recreación, vol. 3, 31-36.

Reese, L.; Kroesen, K. y Gallimore, R. (2000). Agency and School Performance among Urban Latino Youth. En R. Taylor y M. Wang, Resilience Across Contexts: Family, Work, Culture and Community. (pp. 295-332). New Jersey: Erlbaum.

Rodríguez, C. (2010). La igualdad y la diferencia de género en el currículum. En G. Sacristán, Saberes e incertidumbres sobre el currículum (pp.103-127). Madrid: Morata.

Santos, M. (2000). El harén pedagógico. Perspectiva de género en la organización escolar. Barcelona: Graó.

Torres, J. (2010). Currículum, justicia e inclusión. En G. Sacristán, Saberes e incertidumbres sobre el currículum (pp. 84-102). Madrid: Morata.

Trigueros, C. (2000). Nuevos significados del juego tradicional en el desarrollo curricular de la educación física en centros de educación primaria de Granada. (Tesis doctoral). Universidad de Granada, Granada, España.

Tubert, S. (2003). Del sexo al género. Los equívocos de un concepto. Valencia: Ediciones Cátedra.

UNESCO. (2005). Guidelines for inclusion: Ensuring Access to Education for All. París: UNESCO. Fecha de consulta: Febrero $20 / 2012$. En: http://unesdoc.unesco.org/images/0014/001402/140224e. pdf

Varela, J. (1997). El nacimiento de la mujer burguesa. Madrid: La piqueta. 
